\title{
Who is a candidate for a left ventricular assist device? Everyone?
}

\author{
Mani A. Daneshmand, MD
}

\footnotetext{
From the Division of Cardiothoracic Surgery, Department of Surgery, Duke University, Duke University Medical Center, Durham, NC.

Disclosures: Author has nothing to disclose with regard to commercial support.

Received for publication April 13, 2017; accepted for publication April 21, 2017; available ahead of print May 24, 2017.

Address for reprints: Mani A. Daneshmand, MD, Division of Cardiothoracic Surgery, Department of Surgery, Duke University, DUMC 3867, Duke South, Blue Zone, Room 4554, 40 Duke Medicine Circle, Durham, NC 27710 (E-mail: mani.daneshmand@duke.edu).

J Thorac Cardiovasc Surg 2017;154:1319

$0022-5223 / \$ 36.00$

Copyright (C) 2017 by The American Association for Thoracic Surgery

http://dx.doi.org/10.1016/j.jtcvs.2017.04.058
}

In this issue of the Journal, Entwistle ${ }^{1}$ provides us with a thorough ethical analysis of left ventricular assist device (LVAD) therapy for end-stage heart failure. Despite a recent spike in heart transplantation (3191 heart transplants in 2016), almost 4000 patients still remain on the waiting list, and more than 900,000 new patients in the United States have heart failure diagnosed annually.,3 As the number of patients alive with heart failure grows, the demand for LVAD therapy increases exponentially. In fact, in 2016, more than 2400 patients received durable LVAD devices, as reported by the Interagency Registry for Mechanically Assisted Circulatory Support. It is predicted that by the year 2030, there will be more than 8 million patients with heart failure alive in the United States. $^{2}$ As Entwistle ${ }^{1}$ points out in this analysis, we have clear medical guidelines of candidacy for LVAD therapy, but we are limited in ethical guidance. Because of the relatively high financial and systematic burdens of LVAD therapy, it is important to provide this therapy fairly and justly.

Entwistle $^{1}$ uses 2 fictional cases while guiding the reader through the 4 principles of Beauchamp and Childress's framework ${ }^{4}$ for biomedical ethics. With these tools, Entwistle $^{1}$ concludes that LVAD therapy is ethically appropriate for all patients at low risk and conditionally appropriate for patients high risk if they are young. Although it is easy to agree that patients at low risk are most likely to benefit from LVAD therapy, we must be careful in how we handle patients at high risk. Specifically, the "fair innings" argument is far too simplistic a tool really to help clinicians decide which patients at high risk deserve an attempt at "rescue." When it comes to high-risk, hightherapy?

\section{References}

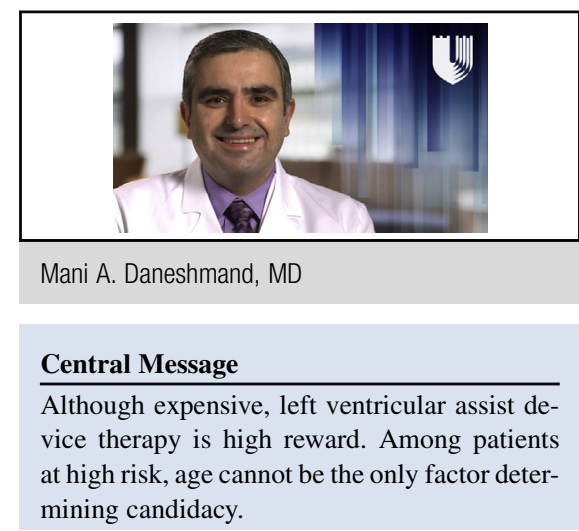

See Article page 1315.

reward scenarios, the devil is in the details. If we imagine the same 2 scenarios that Entwistle ${ }^{1}$ proposed, but this time, the 40-year-old is a single man with no children and the 70-year-old is the sole provider for his disabled daughter and her young children, does this change who we, as stewards of healthcare resources, consider most deserving of the

It is clear that LVADs have become an integral tool in the treatment of end-stage heart failure. As we look to the future, it is imperative that we focus our efforts on improving the cost effectiveness of this therapy. In the meantime, however, determining who is "most deserving" will continue to be a daily challenge.

1. Entwistle JW III. The American Association for Thoracic Surgery 2016 Ethics Forum: "cost-effectiveness and the ethics of left ventricular assist device therapy." J Thorac Cardiovasc Surg. 2017;154:1315-8.

2. Writing Group Members, Mozaffarian D, Benjamin EJ, Go AS, Arnett DK Blaha MJ, Cushman M, et al; American Heart Association Statistics Committee; Stroke Statistics Subcommittee. Heart disease and stroke statistics-2016 update: a report from the American Heart Association. Circulation. 2016;133:e38-360. Erratum in: Circulation. 2016;133:e599.

3. United Network for Organ Sharing. OPTN data as of April 12, 2017. Available at: https://www.unos.org/data/transplant-trends/\#transplants_by_organ_ type+year+2016. Accessed April 12, 2017.

4. Beauchamp TL, Childress JF. Principles of biomedical ethics. 1st ed. New York: Oxford University Press; 1979. 